\title{
Bolt Connection Establishing Model Method and Shock Response Comparison in Diesel Fixed Assembly
}

\author{
Yu-peng Sun \\ Power Engineering College, \\ Naval University of Engineering \\ Wuhan, China, 13346273330 \\ 723438929@qq.com \\ De-bin Zhu \\ Power Engineering College, \\ Naval University of Engineering \\ Wuhan, China
}

\author{
Jian-hua Zhao \\ Power Engineering College, \\ Naval University of Engineering \\ Wuhan, China \\ Liang-gao Pan \\ Military Representative Bureau \\ Naval Equipment Department in Nanjing Distinct \\ Nanjing, China ,15527867463 \\ zhaojh402@sina.com
}

\begin{abstract}
Bolt connection is one of the common connection methods in diesel engine. The purpose of this study is to verify the difference of considering the bolt connection or not in the shock response calculation. The methods applying in the study as following: first design the comparison test of welding connection and bolt connection; establish the diesel engine's fasten component model of considering bolt connection and model without considering bolt connection; then calculate the shock response of the two kinds of model by DDAM method; and finally coupling the shock response in three direction. The above tests reach the result that: the natural frequency of model without considering bolt connection is higher than that of the model considering bolt connection; the rigid connection area will easily produce stress concentration; and the stress concentration can be effectively reduced by considering bolt connection. Therefore, the study suggest that bolt connection should be considered in the study of shock response calculation of diesel engine frequency domain.
\end{abstract}

Keywords-component; DDAM ; Bolt connection ; Shock response; Diesel engine

\section{INTRODUCTION}

Due to the complicated structure 、 the complex movement 、 the various loads it bears and lots of weak links of shock, the diesel engine's shock resistance calculation should consider many factors. The connection between the components and the contact structure influence the transfer of shock load, and the influence needs to analysis in theory and by simulation. As we know, bolt connection is the most common connection method applying in diesel engine. The key link of diesel engine's shock resistance calculation is the whole engine's shock load transfer characteristics and itself shock security $^{[1]}$.

This work is supported by the Fundamental "During the 12th Five-Year Plan National defense pre-research plan” (4010304030202).
The current studies of diesel engine's shock resistant were basically not consider bolt connections, instead their designed diesel engine as one whole rigid equipment ${ }^{[2]}$. This method leads the a higher result when calculate the model's whole stiffness, and influences the shock load's distribution as calculated by frequency domain method. This paper takes the following methods: designed comparison test between welding connection and bolt connection; separately built the fasten component model of considering bolt connection and without considering it; applied DDAM method calculate shock response stress of the two models; phase-coupled response stress to shock in three directions ${ }^{[3]}$.

\section{COMPARISON TEST STUDY}

According to the natural frequency coherence principle of diesel engine in the whole, this study designed a test model imitating diesel engine's feet, as shown in figure. The two sides of test model's feet were separately apply welding connection and bolt connection. Then, study the welding connection's influence to the whole mode's situation and correspondingly study the bolt connection's. Test1 bolt connection machine feet, $150 \mathrm{~N} \cdot \mathrm{M}$ pre-tightening force pre-tighten; Test 2 welding connection machine feet. Then, by experimenting mode test, its test analysis results are shown in figure1.
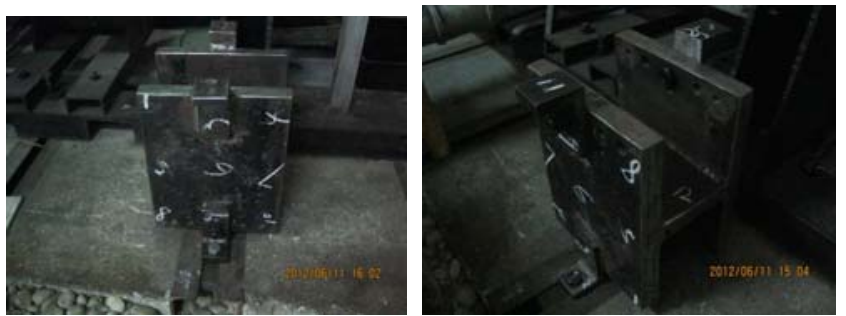

Figure 1 Bolt connection and Welding connection test model 
TABLE 1 NATURAL FREQUENCY OF WELDING CONNECTION AND BOLT CONNECTION

\begin{tabular}{|c|c|c|c|}
\hline frequency & welding & bolts & Relative difference \\
\hline 1 & 49.98 & 49.90 & 0.1 \\
\hline 2 & 150.91 & 170.15 & 12.2 \\
\hline 3 & 294.47 & 289.42 & 1.7 \\
\hline 4 & 481.28 & 455.97 & 5.4 \\
\hline 5 & 670.44 & 667.84 & 0.4 \\
\hline 6 & 834.74 & 772.29 & 8.0 \\
\hline
\end{tabular}

As shown in table 1, the second order frequency value of welding connection is less than that of bolt connection, while, other order welding's frequency were all higher than that of bolt connection. This verifies the flexibility of bolt connection is greater than that of welding connection and the natural frequency domain of welding connection is higher than that of bolt connection. In the finite element calculation, if apply the paste or welding connection instead of bolt connection, thus the flexibility which is not consider bolt connection will lead the model's stiffness larger and the final natural frequency will larger than the actual situation.

\section{THE SHOCK RESPONSE SIMULATED CALCULATION}

\section{A. Model establishment}

When calculating model 1 , the test directly treated the connected component as a whole without considering bolt connection, which is the most frequent applying method in the current study of diesel engine shock response. This method has the connection characteristics of without consider the bolt connection's connection component during the course of model establishment.

When calculating model 2, considering bolt connection, the test is made by applying the beam unit of bolt bar, then coupled the bolt contact area's node DOF through spring unit and rigid unit. Through this way, the test can reflect the bolt connection structure's dynamic characteristics, and can save large amount of computer resources, make the complicated nonlinear problem linearization. as shown in figure2.

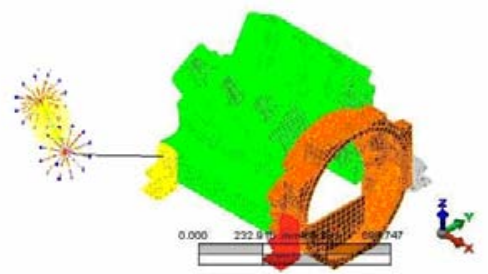

Figure 2. machine feet bolt connection finite element model

Taking one type of six cylinder engine as the research object, the test built the three-dimensional entity model and finite element analysis model based on professional software. As shown in figure 1, using the hexahedral and tetrahedron mixing unit divide the machine body, flywheel shell, machine feet into mesh, altogether divides the 254780 units and 176054 nodes. Model 1 defines the paste contact relations among machine feet, body, flywheel shell and other components(the corresponding node on the surface share DOF); Model 2 defines that the connection between machine and its feet applies bolt connection model, the paste contact relations is between flywheel shell and machine. The equivalent treatment method is that the structure of crankshaft and the cylinder cover and other parts in the body of machine apply add quality unit in machine's barycenter position. Diesel engine's all components' materials are shown in table 2.

TABLE 2. DIESEL ENGINE'S ALL COMPONENTS' MATERIALS

\begin{tabular}{|c|c|c|c|c|}
\hline component & $\begin{array}{c}\text { Machine } \\
\text { body }\end{array}$ & $\begin{array}{c}\text { Machine } \\
\text { feet }\end{array}$ & $\begin{array}{l}\text { Flywheel } \\
\text { shell }\end{array}$ & $\begin{array}{l}\text { Machine } \\
\text { feet bolts }\end{array}$ \\
\hline material & HT300-Cu-Cr & 35 hao steel & HT250 & 45hao steel \\
\hline$\rho\left(\mathrm{kg} / \mathrm{m}^{3}\right)$ & 7800 & 7850 & 7340 & 7810 \\
\hline$E(G P a)$ & 157 & 212 & 155 & 200 \\
\hline$v$ & 0.27 & 0.31 & 0.27 & 0.27 \\
\hline$\sigma_{s}(M P a)$ & 900 & 315 & 850 & 355 \\
\hline
\end{tabular}

Supposing that diesel engine apply rigid installation, adding fixed constraint at machine feet, loading $20000 \mathrm{~N}$ pre-tighten load in the connection bolts between machine feet and machine itself.

\section{B. CALCULATION BY DYNAMIC DESIGN ANALYSIS METHOD}

DDAM is short of dynamic design analysis method which is based on the superposition. of structure vibration mode. The equipment was simplified to muti-DOF system. After calculating the model's vibration shape and model quality, then the test got model's displacement and stress by input the basic shock spectrum; and got the equipment's displacement and stress response by synthesis of mode solution. The DDAM calculation steps of Marine equipment shock response ${ }^{[4]}$.

According to the GJB1060 rule, diesel engine which is installed on the surface ship, its shock resistant level is $\mathrm{A}$. The installation part is the hull parts and should undertake spring analysis. Shock design input spectrum as shown in table 3:

TABEL 3. SHOCK DESIGN INPUT SPECTRUM

\begin{tabular}{cccc}
\hline $\begin{array}{c}\text { Equipment } \\
\text { installation } \\
\text { position }\end{array}$ & Shock direction & \multicolumn{2}{c}{ Spring design } \\
& & $\mathrm{A}_{\mathrm{a}}$ & $\mathrm{V}_{\mathrm{a}}$ \\
\hline \multirow{2}{*}{ hull } & Vertical & $1.0 \mathrm{~A}_{0}$ & $1.0 \mathrm{~V}_{0}$ \\
& Horizontal & $0.4 \mathrm{~A}_{0}$ & $0.4 \mathrm{~V}_{0}$ \\
& Longitudinal & $0.2 \mathrm{~A}_{0}$ & $0.2 \mathrm{~V}_{0}$ \\
\hline
\end{tabular}

To the hull installation position:

$$
\begin{gathered}
A_{a}=A F \cdot A A=\frac{\left(A B+M_{\Omega}\right)\left(A C+M_{\Omega}\right)}{\left(A D+M_{Q}\right)^{2}} \\
V_{\alpha}=V F \cdot V A \frac{\left(V B+M_{\Omega}\right)}{V C+M_{\Omega}}
\end{gathered}
$$

Among them: VF, AF is coefficient; VA, VB, VC, AA, AB, $\mathrm{AC}, \mathrm{AD}$ respectively is speed spectrum and acceleration spectrum constant. $M_{a}$ is effective model quality. Critical frequency $\omega_{c}=A_{a} g / V_{a}$ higher than the critical frequency, 
design the SRS as acceleration spectrum, below critical frequency, design the SRS as speed spectrum.

\section{C. calculation result}

According to the standard requirement of shock, the study calculated the shock's first 20 modes according to the shock higher than $80 \%$ mode's choose standard. When shock happens in different directions, modes whose participation grade is higher than $1 \%$ among the 20 modes, their mode frequency, mode quality, its percentage and shock design acceleration value, see table $4-5$.

TABLE 4. MODEL WITH BOLT CONNECTION

\begin{tabular}{|c|c|c|c|c|c|c|c|c|c|c|c|c|c|c|}
\hline \multicolumn{2}{|c|}{ longitudinal direction } & \multicolumn{3}{|c|}{ X) DDAM shock design acceleration } & \multicolumn{3}{|c|}{ transverse direction ( $\mathrm{Y})$ DDAM } & \multicolumn{2}{|c|}{ shock design acceleration } & \multicolumn{5}{|c|}{ Vertical direction（Z） DDAM shock design acceleration } \\
\hline Modal & FrequencylHz & $\begin{array}{l}\text { Modal } \\
\text { masskg }\end{array}$ & Percentage $1 \%$ & Acceleratedlg & Modal & FrequencylHz & $\begin{array}{l}\text { Modal } \\
\text { mass kg }\end{array}$ & Percentage $\%$ & Acceleratedlg & Modal & FrequencylHz & $\begin{array}{l}\text { Modal } \\
\text { masskkg }\end{array}$ & Percentagel\% & Acceleratedlg \\
\hline 1 & 323.13 & 129.59 & 37.67 & 30.61 & 1 & 323.13 & 119.62 & 34.77 & 63.09 & 3 & 485.41 & 154.44 & 44.89 & 142.70 \\
\hline 2 & 355.39 & 156.28 & 45.43 & 28.39 & 2 & 355.39 & 109.33 & 31.78 & 65.13 & 4 & 512.88 & 95.74 & 24.83 & 170.20 \\
\hline 6 & 736.34 & 12.04 & 3.5 & 47.27 & 5 & 577.56 & 62.96 & 18.30 & 76.42 & 8 & 828.71 & 11.98 & 3.48 & 236.40 \\
\hline 8 & 828.28 & 5.51 & 1.6 & 48.75 & --- & --- & --- & --- & --- & 10 & 1026.99 & 6.52 & 1.90 & 242.60 \\
\hline
\end{tabular}

TABLE 5. MODEL WITHOUT BOLT CONNECTION

\begin{tabular}{|c|c|c|c|c|c|c|c|c|c|c|c|c|c|c|}
\hline \multicolumn{2}{|c|}{ longitudinal direction } & \multicolumn{3}{|c|}{ (X) DDAM shock design acceleration } & \multicolumn{2}{|c|}{ transverse direction } & \multirow{2}{*}{$\begin{array}{l}\text { Y) DDAM } \\
\begin{array}{l}\text { Modal } \\
\text { mass } k g\end{array}\end{array}$} & \multicolumn{2}{|c|}{ shock design acceleration } & \multicolumn{5}{|c|}{ Vertical direction（Z) DDAM shock design acceleration } \\
\hline Modal & FrequencylHz & $\begin{array}{c}\text { Modal } \\
\text { massikg }\end{array}$ & Percentagel\% & Acceleratedig & Modal & FrequencylHz & & Percentagel\% & Accelerated $\backslash g$ & Modal & Frequency'Hz & $\begin{array}{l}\text { Modal } \\
\text { masskg }\end{array}$ & Percentagel\% & Accelerated $\backslash g$ \\
\hline 1 & 327.43 & 97.82 & 30.82 & 33.80 & 1 & 327.43 & 139.51 & 43.96 & 59.49 & 3 & 490.14 & 167.90 & 52.90 & 137.60 \\
\hline 2 & 362.51 & 175.83 & 55.40 & 26.97 & 2 & 362.51 & 85.49 & 26.94 & 70.47 & 4 & 521.24 & 813.23 & 25.62 & 178.70 \\
\hline 6 & 726.54 & 9.73 & 2.95 & 47.87 & 5 & 594.27 & 57.06 & 17.98 & 78.15 & 7 & 793.45 & 4.99. & 1.57 & 244.40 \\
\hline 7 & 793.45 & 4.76 & 1.51 & 48.93 & 9 & 907.67 & 6.14 & 1.93 & 97.22 & 8 & 838.32 & 9.47 & 2.99 & 239.20 \\
\hline
\end{tabular}

From the mode calculation results shown on the above table 4-5, the study found that the natural frequency of model without bolt connection is higher than that of the model with bolt connection, and due to that cause the mode's quality distribution was influenced, thus affected shock load's loading.

\section{THE STUDY OF RESULTS COMPARISON}

From the calculation results shown as figure $3 、 4$, the study found that the maximum stress was $611.78 \mathrm{MPa}$ when without considering bolt connection, and the maximum stress position appeared at the rigid connection part between the body and machine feet where appears local stress concentration. The maximum stress is $473.07 \mathrm{MPa}$ when consider bolt connection. Therefore, the study found that the stress concentration could be effective reduced by considering bolt connection.

From the calculation results shown as figure 4, D、E、F are the shock response results after the diesel engine be functioned with three-direction coupling. The shock response

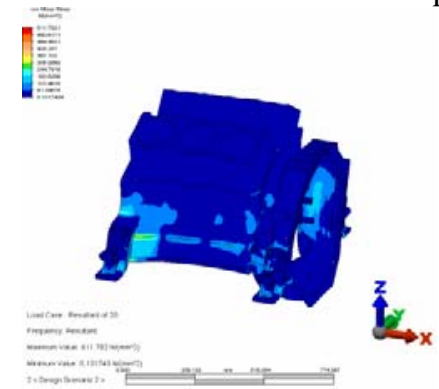

A shock response of three-direction coupling

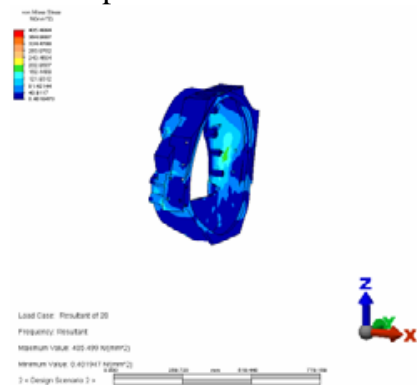

B shock response of flywheel shell three-direction coupling under the function of with three-direction coupling is obviously higher than signal-direction's shock loading. Diesel engine machine feet under greater inertia force, its biggest stress value reached to $464.05 \mathrm{MPa}$. Machine feet can bear the amount of stress almost same like the machine, but because the static yield strength of machine feet material is comparatively small, so the machine feet component should change to the material with stronger yield strength.

The machine and its feet adopted spring-beam bolt connection model. Through calculation, the test got that the maximum stress on the bolt connection' [s axial direction is 28.04MPa, which is less than the material ultimate yield. The Axial force of bolt connection is $3888.14 \mathrm{~N}$, its value is less than bolt pre-tighten force $20000 \mathrm{~N}$, therefore the machine feet's bolts are safe.

Figure 3. shock response of rigid connection three-direction coupling

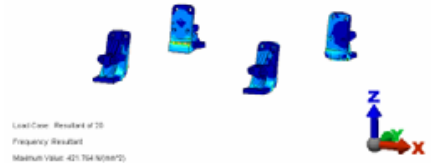

C shock response of Machine feet three-direction coupling 


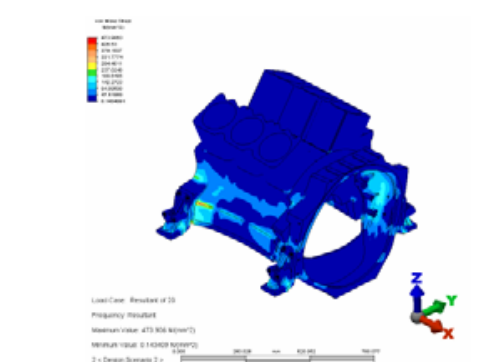

D shock response of three-direction coupling

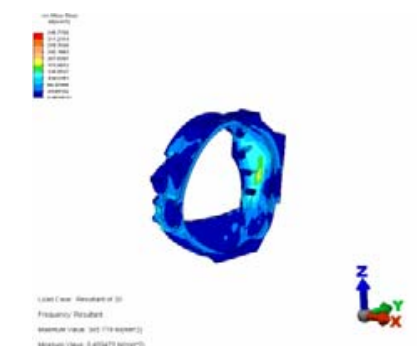

E shock response of flywheel shell three-direction coupling

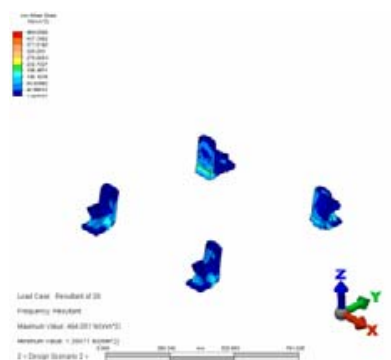

F shock response of Machine feet three-direction coupling

Figure 4. shock response of spring-beam three-direction coupling

\section{CONCLUSION}

This paper respectively set up finite element model of diesel engine fasten component with consider bolt connection and without bolt connection, verified the difference between bolt connection and welding connection through mode test, calculated the shock response of diesel engine fasten component by DDAM method. The study got the conclusion as following:

a) Through test model analysis, verified the flexibility of bolt connection is greater than that of welding connection, and the natural frequency of model considering bolt connection is less than that of model without considering bolt connection.

b) Diesel engine skirt and machine feet, where the shock response is bigger, its inertia force is big and it's the sensitive area of mode. diesel engine machine feet's stress is bigger than the material's ultimate yield strength, therefore, diesel engine machine feet should choose materials with high yield strength. c) The natural frequency of model without considering bolt connection is higher than that of model considering bolt connection, and the connection area of the mode without considering bolt connection would easily produce stress concentration which lead the stress value to large. This should be attention in frequency domain analysis

\section{REFERENCES}

[1] Ji Chen, Wang Yu, ZhaoJianhua,et al. Journal of Vibration and Shock, 2009, 29(11): 171-176.

[2] Wilson J F, Callis E G. The dynamics of loosely jointed structures[J]. International Journal of Non-linearMechanics, 2004, 39(3): 503-514

[3] FerasA, Pierre S, Alain D. Equivalent axial stiffness of various components in bolted joints subjected to axial loading[J]. Finite Element in Analysis and Design, 2007, 43(8): 589-598

[4] ChenHailong, YaoXiongliang, ZhangAman, et al. Journal of Vibration and Shock, 2009, 28(2): 45-50. 